\title{
125. On Malignolipin. VIII
}

\section{Optical Properties of Some Derivatives of Malignolipin*)}

\author{
By Takekazu Kôsaki, Shinya NAKagawa, and Toshiko SaKa \\ Department of Biochemistry, \\ Mie Prefectural University School of Medicine, Tsu \\ (Comm. by Y. Kuno, M.J.A., Oct. 12, 1960)
}

Optical properties of some derivatives of malignolipin have been examined to add evidence useful in identification. Authentic samples of malignolipin picrate, as well as the ammonium salt of malignolipin obtained by the method described in the preceding report, ${ }^{1)}$ and of the fatty acid obtained from the ammonium salt of malignolipin by its acid hydrolysis were examined.

Ultraviolet spectroscopy. Malignolipin picrate has two absorptions which are quite similar to those of picric acid, but only a little shifted to the long wave length side in that of $364 \mathrm{~m} \mu$ one. An ammonium salt of malignolipin has an absorption, which can also be found in other

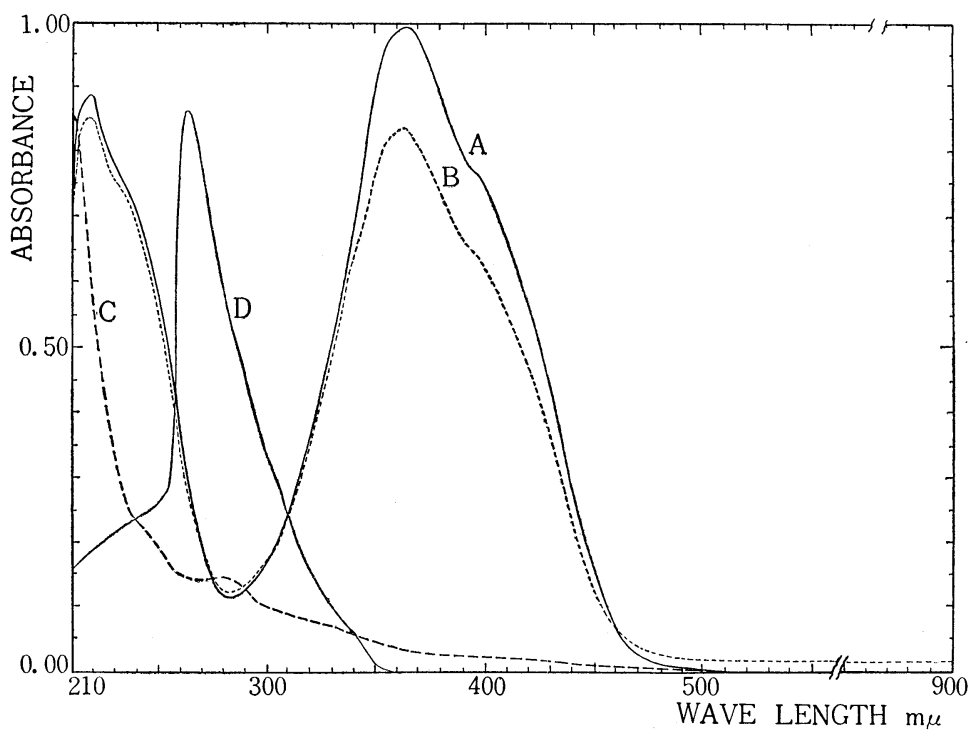

Fig. 1. Absorption spectra
- A. Malignolipin picrate (in ethanol)
B. Picric acid ( , )
-..- C. Ammonium salt of malignolipin (in water)
D. A fatty acid of malignolipin (in $\mathrm{CCl}_{4}$ )

*) In part, aided by Grant No. C-4795 from the National Institute of Health,
United States Public Health Service, and also by Grants from the Ministry of Educa-
tion, Shionogi Co., and Upjohn Co.

1) Kôsaki, T., Nakagawa, S., and Saka, T.,: Proc. Japan Acad., 36, 362 (1960). 
phospholipids. The fatty acid of malignolipin has a relatively sharp and strong absorption near $263 \mathrm{~m} \mu$, which suggests its high unsaturation or an existence of a couple of conjugate double bonds (cf. Fig. 1).

Visible spectroscopy. Malignolipin picrate, ammonium salt of malignolipin, and the fatty acid of malignolipin have no absorption maximum in this region.

Near-infrared spectroscopy. Although picric acid has several absorptions in this region, malignolipin picrate has only one, which corresponds to one of the absorptions of picric acid, indicating that the vibration of some groups of picric acid is restricted by the combination with malignolipin (cf. Fig. 2). Ammonium salt of malignolipin, and the fatty acid of malignolipin have no absorption in this region.

Infrared spectroscopy. Malignolipin picrate, ammonium salt of malignolipin, and the fatty acid of malignolipin show respectively characteristic patterns of absorption spectra, quite different from those of various chemical substances hitherto reported, and they can serve as criteria for identification (cf. Fig. 3). The absorption spectra of the mentioned substances with the samples obtained from different kinds of

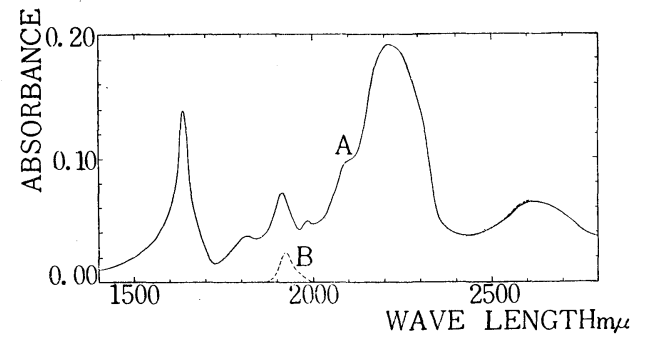

Fig. 2. Near-infrared spectra

A. Picric acid (in acetone)

B. Malignolipin picrate ( , )

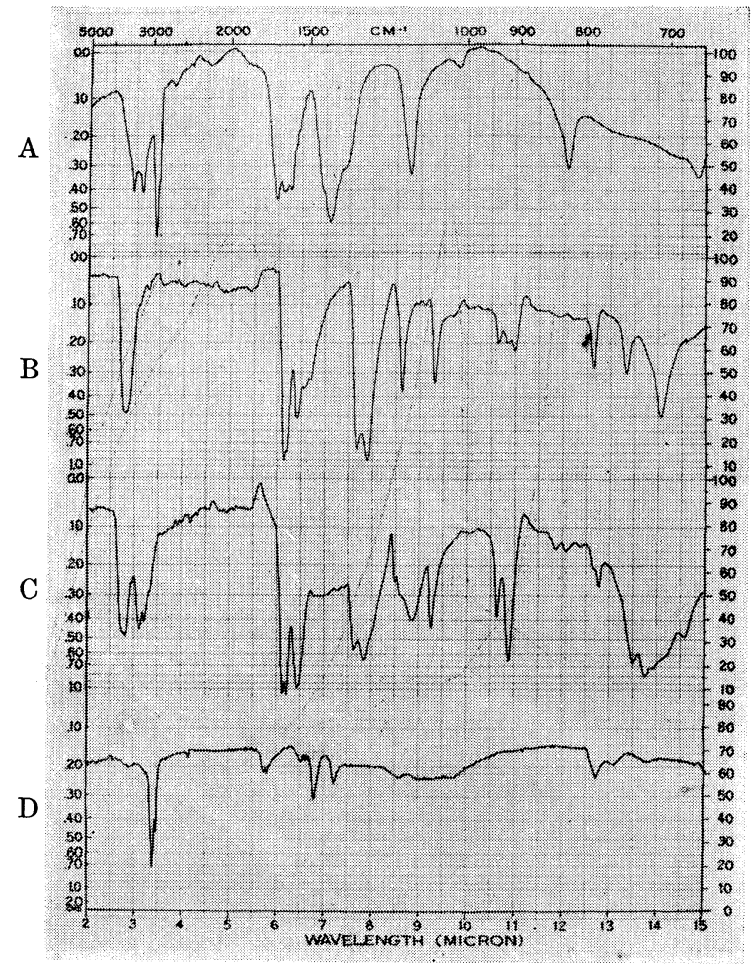

Fig. 3. Infrared spectra

A. Ammonium salt of malignolipin (in paraffin oil)

B. Malignolipin picrate (in acetone)

C. Picric acid ( ,, )

D. A fatty acid of malignolipin (in potassium bromide disk) 
malignant tumors are ascertained to be quite similar to one another; that is, the malignolipin from different sources is identical in respect to its infrared absorption spectrum, and to its other properties which have been previously reported. ${ }^{1}$ " In the infrared spectrum of the ammonium salt of malignolipin, bands at $2.91 \mathrm{~m} \mu$ and $3.15 \mathrm{~m} \mu$ are probably assigned to the stretching vibration of $\mathrm{N}-\mathrm{H}$, that at $3.4 \mathrm{~m} \mu$ to the $\mathrm{C}-\mathrm{H}$ stretching vibration, those at $5.95 \mathrm{~m} \mu, 6.1 \mathrm{~m} \mu$, and $6.3 \mathrm{~m} \mu$ to the carboxylic acid amide group, those at about $7.1 \mathrm{~m} \mu$ to the bending vibration of $\mathrm{CH}_{2}$ and $\mathrm{CH}_{3}$, those at $8.8 \mathrm{~m} \mu$ and $9.85 \mathrm{~m} \mu$ to the phosphoric acid ester, and that at $12.1 \mathrm{~m} \mu$ to $\stackrel{\mathrm{H}}{\mathrm{C}}=\mathrm{C}<$ group, but there can be found no band which can be assigned to the ester group vibration, infrared spectra of other lipids reported by other researchers ${ }^{2 / 3}$ taken also as references. The result agrees well with the tentative structure of malignolipin previously proposed.4)

In the infrared spectrum of a fatty acid of malignolipin, bands at $3.42 \mathrm{~m} \mu$ and $3.51 \mathrm{~m} \mu$ are probably assigned to the $\mathrm{C}-\mathrm{H}$ stretching vibration, that at $5.85 \mathrm{~m} \mu$ to the carboxyl group, those at $6.82 \mathrm{~m} \mu$ and $7.28 \mathrm{~m} \mu$ to the bending vibration of $\mathrm{CH}_{2}$ and $\mathrm{CH}_{3}$, and that at $12.7 \mathrm{~m} \mu$ $\mathrm{H}$ to $-\mathrm{C}=\mathrm{C}<$ group.

In conclusion, the results offer some criteria for the identification of malignolipin, and also demonstrate the uniqueness of malignolipin as a chemical entity. Malignolipin isolated from different kinds of malignant tumors appears to be identical.

2) Freeman, N. K., Lindgren, F. T., Yook, C. N., and Nichols, A. V.,: J. Biol. Chem., 203, 293 (1953).

3) Schwarz, H. P., Dreisbach, L., Childs, R., and Mastrangelo, S. V.,: Ann. New York Acad. Science, 69, 116 (1958).

4) Kôsaki, T., et al.: Science, 127, 1176 (1958). 